\title{
Multiple Ion Counting of Fission Product Ruthenium in Historic Environmental Samples
}

ELISE CONTE, KELLY MCHUGH, CONNOR HILTON, CHRISTOPHER BROWN AND EIRIK KROGSTAD

Pacific Northwest National Laboratory

Presenting Author: connor.hilton@pnnl.com

Characterization of nuclear fuel activities is an evolving area, with continued interest in techniques that permit distant sampling. However, far-field detection is typically limited to atmospheric approaches that suffer from short temporal sampling windows. Downwind accumulation of stable fission products provides the opportunity to assess a record of past nuclear activities. Ruthenium ( $\mathrm{Ru})$ is an ideal candidate, as it is among the most abundant of fission products, has isotopic signatures from uranium $(\mathrm{U})$ versus plutonium $(\mathrm{Pu})$ fission that are distinct from natural $\mathrm{Ru}$, and is released as a volatile, oxide phase. These features of $\mathrm{Ru}$ make it ideal for offsite characterization. Filters collected at Pacific Northwest National Laboratory (WA) during peak Hanford fuel reprocessing periods should have the distinctive $\mathrm{Ru}$ isotopic composition of primarily ${ }^{235} \mathrm{U}$ fission, with limited ${ }^{239} \mathrm{Pu}$ fission, lying on a tie-line between those two endmembers (figure 1). Calculated weekly atmospheric ${ }^{101} \mathrm{Ru}$ concentrations from fuel processing activities at Hanford between 1969-1980 are elevated (based on ${ }^{106} \mathrm{Ru}$ data) in air filters collected over $40 \mathrm{~km}$ away opposite the dominant wind direction from site. Similar, or higher, levels of stable Ru can be anticipated to be present in archived air filters taken in the 300 area of Hanford during this same time interval. We present results for $\mathrm{Ru}$ separated from air filter samples analyzed via multiple ion counting for $\mathrm{Ru}$ isotopic ratios using a $\mathrm{Nu}$ Instruments thermal ionization mass spectrometer (TIMS), an instrument equipped with Zoom lens technology, 16 Faraday detectors, and five ion counters. We have been able to quantitatively determine the natural background isotopic ratios of $\mathrm{Ru}$, as well as measure the variability in $\mathrm{Ru}$ ratios on samples containing ultra-trace levels of $\mathrm{Ru}$. This presentation will cover methods developed for handling, separating, loading, and analyzing $\mathrm{Ru}$ from air filter samples. 